\title{
CONDICIONES LABORALES Y SOCIOECONÓMICAS DE ESTUDIANTES Y EGRESADOS DE UNA INSTITUCIÓN DE EDUCACIÓN SUPERIOR EN EL PERIURBANO DE LA ZONA METROPOLITANA DEL VALLE DE MÉXICO: UN ESTUDIO EXPLORATORIO
}

SOCIO-ECONOMIC AND LABOR CONDITIONS OF STUDENTS AND ALUMNI OF A HIGHER EDUCATION INSTITUTION IN THE PERIURBAN AREA OF THE METROPOLITAN VALLEY

OF MEXICO CITY: AN EXPLORATORY STUDY

\section{CONDIÇÕES SÓCIO-ECONÓMICAS E OBRA DE ESTUDANTES E GRADUADOS DE UMA INSTITUIÇÃO DO ENSINO SUPERIOR NA REGIÃO METROPOLITANO SUBURBAN VALLEY MÉXICO: UM ESTUDO EXPLORATÓRIO}

\author{
Gustavo Mejía Pérez. \\ Óscar Espinoza Ortega ${ }^{2}$
}

\begin{abstract}
RESUMO
O artigo apresenta a análise do trabalho e da situação económica dos diplomados de uma instituição de ensino superior localizada na Região Metropolitana do México. O estudo foi realizado com base em dados fornecidos pelos graduados Institucional Sistema de Acompanhamento da Universidade Autônoma do Estado do México no período 2000-2013. Os resultados da análise mostram uma entrada para o mercado de trabalho diferenciadas por sexo e grau, possivelmente, ele determina itinerários diferentes nos processos de independência família de estudantes e graduados.
\end{abstract}

PALAVRAS-CHAVE: Educação superior. Independência famíliar. Mercado de trabalho.

\section{ABSTRACT}

The paper presents the analysis of the labor and economic situations of alumni from a higher education institution located in the Metropolitan Area of Mexico City. The study anazlyed data provided by the Institutional Alumni Tracking System of the Autonomous University of the State of Mexico from 2000 to 2013. The results of the analysis shows entries into the labor market differentiated by gender and degree, which possibly determine different itineraries in the students' and alumni's processes of family independence.

KEYWORDS: Higher education. Family independence. Labor market.

\footnotetext{
${ }^{1}$ Departamento de Investigaciones Educativas. Centro de Investigaciones y Estudios Avanzados del Instituto Politécnico Nacional (CINVESTAV), México. - E-mail: cabezahidra@gmail.com - ORCID: http://orcid.org/0000-0002-2370-4276

2 Centro Universitario UAEM Valle de Teotihuacán. Universidad Autónoma del Estado de México, México. Email: oeo_21@yahoo.com.mx - ORCID: http://orcid.org/0000-0002-2304-7587
}

Submetido em: 18-11-2016 - Aceito em: 13-12-2016 - Publicado em: 07-02-2017

(C) Rev. Inter. Educ. Sup. Campinas, SP 


\begin{abstract}
RESUMEN
El documento presenta el análisis de la situación laboral y económica de egresados de una institución de educación superior ubicada en el Zona Metropolitana del Valle de México. El estudio se realizó con base en los datos proporcionados por el Sistema Institucional de Seguimiento de Egresados de la Universidad Autónoma del Estado de México en el período 2000-2013. Los resultados del análisis muestran un ingreso al mercado laboral diferenciado por sexo y por carrera, que posiblemente determina diferentes itinerarios en los procesos de independencia familiar de estudiantes y egresados.
\end{abstract}

PALABRAS CLAVE: Educación superior. Independencia familiar. Mercado laboral.

\title{
INTRODUCCIÓN
}

El objetivo de este documento es describir las condiciones socioeconómicas y laborales de los egresados del Centro Universitario UAEM Valle de Teotihuacán (CUVT), durante los estudios y al término de los mismos, con el fin de explorar algunas hipótesis acerca de los procesos de independencia económica que se dan en este periodo. Estos procesos son importantes pues como señalan De Vries y Navarro Rangel (2015), al terminar la escuela preparatoria, los y las jóvenes empiezan a convertirse en adultos, mediante un proceso que involucra las relaciones de pareja, una vivienda independiente de sus padres y la participación en el mercado laboral. La pregunta que surge aquí es si la universidad es un catalizador que dispara estos procesos o sólo un proceso que ocurre de forma paralela a los estudios superiores.

El documento se compone de tres apartados. En el primero se muestra una síntesis de lo que dice la literatura sobre las condiciones laborales y socioeconómicas de quienes acuden y egresan a la universidad en México. En la siguiente sección se describe el caso de estudio, así como la metodología empleada para la investigación. La tercera parte muestra las características laborales y socioeconómicas del grupo estudiado en dos momentos: mientras estudiaban la licenciatura y al término de la universidad. Finalmente, en las conclusiones se discuten, con base en la literatura previa y los datos recopilados, los posibles cambios que la educación superior (ES) generó en los egresados respecto a sus condiciones laborales y su independencia de las familias de origen.

\section{SITUACIÓN LABORAL Y ECONÓMICA DE ESTUDIANTES Y EGRESADOS UNIVERSITARIOS MEXICANOS: UNA BREVE REVISIÓN DE LA LITERATURA}

Con el objetivo de saber qué es lo que dicen los estudios empíricos sobre la situación laboral y económica de estudiantes y egresados universitarios en México, se realizó una búsqueda de investigaciones que abordaran este tópico. Al final de esta búsqueda se encontraron 22 estudios publicados entre 2008 y 2016, en los cuales se utilizaron como marco de referencia las teorías del capital humano (Becker, 1964; Schultz, 1963), competencia por los puestos Thurow (1975), la asignación (Sattinger, 1993) y la reproducción social (Bourdieu y Passeron, 1979). Las metodologías y técnicas utilizadas incluyen encuestas, entrevistas, análisis de fuentes secundarias y revisión bibliográfica. De los 22 estudios sólo cuatro hacen referencia al contexto donde se realiza la investigación: tres se realizan en espacio urbanos y uno en un medio rural. 
La información que a continuación se presenta se organiza en dos grandes apartados: el trabajo de los estudiantes durante la licenciatura y condiciones laborales y económicas de los egresados.

\section{Las características demográficas y el trabajo de los estudiantes durante la licenciatura}

En un estudio realizado en el Centro Universitario de Los Altos, de la Universidad de Guadalajara (UDG), los egresados de contaduría (generación 2008-2012) son jóvenes que en su mayoría ronda los 24 y 25 años de edad y se inscribieron a la universidad después de haber terminado la educación media superior (GONZÁLEZ PÉREZ; GONZÁLEZ FRANCO, 2015). Según los resultados de esta investigación hay una diferencia notable en el estado civil de acuerdo al sexo: el $61 \%$ de las mujeres y el 11\% de los hombres están casados.

En el mismo campus de Los Altos, González Anaya y Carrillo Torres (2016) encontraron que en la carrera de psicología (generación 2008-2012) la mayoría de los estudiantes son originarios de municipios o localidades de la Región Altos Sur, las cuales son poblaciones de tipo rural en muchos de los casos. Además identificaron que la población analizada tiene entre 24 y 27 años de edad. El $28.57 \%$ de los entrevistados son varones, de los cuales solo $12.5 \%$ están casados, y el resto, es decir, $71.42 \%$ son mujeres, de las cuales 17.85 $\%$ están casadas.

En otro estudio en la UDG, Enciso Ávila (2013) identificó que la distribución entre hombres y mujeres de los graduados persiste una ventaja de $8 \%$ a favor de las mujeres. En esta universidad los estudiantes de la UDG provienen mayoritariamente de familias no universitarias, es decir, son la primera generación de la familia que accede a la universidad y se gradúa. Además, casi la mitad de ellos, el $40 \%$, proviene de familias cuyos padres tienen como máximo estudios primarios. Sin embargo, entre sus graduados están sobrerrepresentados aquellos cuyos padres tienen niveles educativos medios y superiores, mientras que están subrepresentados los que sólo disponen de estudios primarios.

De acuerdo con un estudio realizado en la UDG, se pudo ver que la mayoría de los alumnos inician su itinerario laboral durante los estudios, y las situaciones mixtas de estudios y trabajo continúan presentes años después del egreso (PLANAS COLL, 2013). También en la UDG, Carrillo Regalado y Ríos Almodóvar (2014) realizaron un análisis comparativo de los factores que explican la condición laboral y la jornada de trabajo de los estudiantes, mediante el empleo de modelos de regresión probabilístico, soluciones de mínimos cuadrados ordinarios y datos de la Encuesta UDG y la Encuesta Nacional de Ocupación y Empleo (ENOE). En sus resultados encontraron una gran diferencia en las proporciones de participación laboral que presentan los alumnos de licenciatura de la UDG en comparación con el promedio de universidades de México: 43\% de los alumnos de la UDG trabajan, mientras que hacen lo mismo $35 \%$ en promedio nacional. En cuanto a la explicación de la condición laboral del estudiante (desempeñarse o no en el mercado de trabajo), el factor más determinante es la carrera que cursan en la universidad, la cual es decisiva para que incursionen o no activamente en la economía. En el caso de la UDG las carreras que presentan mayor propensión al trabajo de los estudiantes son las de los centros universitarios de Ciencias Económico Administrativas, Ciencias Biológicas y Agropecuarias, Ciencias Sociales y Humanidades, y Ciencias Exactas e Ingenierías. Otros factor determinante de la condición laboral de los estudiantes es la transferencia de dinero de los padres a los alumnos, si estos ingresos no laborales se incrementan los alumnos podrían desistir de participar en el

(C) Rev. Inter. Educ. Sup. Campinas, SP p.66-89 jan./abr. 2017 ISSN 2446-9424 
mercado laboral. Finalmente, el sexo es una variable determinante para la amplitud de la jornada laboral, en el sentido de que ser hombre repercute en una mayor cantidad de horas trabajadas por jornada laboral.

En un análisis previo realizado por Carrillo Regalado y Ríos Almodóvar (2009), a partir de la ENOE 2004, se mostró que la condición de trabajar o no es afectada por las transferencias del jefe del hogar a los estudiantes (o ingresos no laborales) y el sexo del estudiante (ser hombre), pues son las variables que determinan en mayor medida la condición laboral. Además, hay otros factores que también intervienen en esta condición, tales como la escolaridad del jefe del hogar, la edad del estudiante y disciplina de la licenciatura que cursan. En este estudio la población estudiantil estuvo compuesta de $51 \%$ de hombres y el resto fueron mujeres, aunque los estudiantes hombres que trabajan son más que las mujeres ( $26 \%$ frente a $17 \%$ de las mujeres) lo cual implica que poco más de tres quintos del total de puestos laborales ocupados por estudiantes sean desempeñados por hombres.

A pesar de que en el imaginario se cree que el que un estudiante de licenciatura trabaje es un factor negativo para su desarrollo, la condición del estudiante que trabaja tiene implicaciones diversas entre las que se pueden identificar procesos de agobio y sacrificio, pero también de satisfacciones y orgullo personal. E incluso estos trabajos pueden significar la integración de saberes de distinto origen -escolar y laboral- para el desarrollo de competencias, que implica una conjunción de conocimientos, habilidades, actitudes y valores orientados al desempeño social y profesional, además de funcionar como un puente con los mercados de trabajo, las necesidades del entorno y el desarrollo laboral y personal. Estos fueron algunos de los resultados del estudio realizado por Cuevas y De Ibarrola (2013) con estudiantes del Instituto Tecnológico de una ciudad del centro del país que se encontraban cursando los últimos semestres en las áreas de Ingeniería, Administración e Informática.

El ingreso al mercado de trabajo entre las personas que acuden a la universidad puede darse al término de los estudios o en el transcurso de los mismos, como lo muestran De Vries y Navarro Rangel (2015) en el análisis realizado con base en los datos obtenidos del proyecto El Profesional Flexible en la Sociedad del Conocimiento (Proflex), en el que participaron nueve universidades mexicanas (seis públicas y tres privadas). De acuerdo con De Vries y Navarro Rangel (2015), la mayoría de los egresados tuvo experiencias laborales relacionadas con sus estudios, aparte de las prácticas profesionales. Incluso un $24.9 \%$ de los estudiantes indica que los estudios no eran su actividad principal en los últimos dos años de su carrera.

Los resultados presentados en el trabajo anterior coinciden con lo encontrado por González Pérez y González Franco (2015) en el Centro Universitario de Los Altos, en el que la gran mayoría de los egresados de la carrera de contaduría se sostuvo económicamente durante su formación universitaria. Las cifras son distintas en el caso de los egresados de psicología del mismo campus, de acuerdo con González Anaya y Carrillo Torres (2016), sólo el $16 \%$ fue autosuficiente económicamente durante la carrera y el resto dependía de la beca, los padres o el cónyuge. Esta investigación muestra que sólo el $21 \%$ de los padres y el $11 \%$ de las madres cuentan con estudios de licenciatura o superiores.

Sin embargo, no todos los estudios apuntan a señalar las diferencias laborales entre hombres y mujeres, de acuerdo con un estudio sobre trayectorias laborales realizado en la UDG por Planas Coll (2013); en términos de calidad de la inserción para los egresados que están ocupados al final de su itinerario, no se observan diferencias significativas, ni por 
sexos, ni por orígenes sociales. En cambio, sí se observan diferencias significativas relacionadas con el sexo de los egresados, pero no con su origen social, en el grado de actividad y de ocupación, de tal forma que se puede inferir que trabajar durante los estudios no es un comportamiento ni de pobres ni de hombres (PLANAS COLL; ENCISO ÁVILA, 2013).

\section{Condiciones laborales y económicas de los egresados}

El estudio de Burgos Flores y López Montes (2010), realizado con egresados de la Universidad de Sonora, encontró que el problema más grave no es el desempleo de profesionistas, sino las condiciones en las que se insertan en el mercado de trabajo: una proporción importante de ellos no obtiene remuneraciones adecuadas; se desempeña en puestos de carácter no profesional; ocupa un puesto para el cual no se requería de estudios de nivel superior; el empleo que desarrolla no tiene mucha coincidencia con la carrera estudiada; y no aplica plenamente los conocimientos y habilidades adquiridos en la universidad. Este mismo estudio mostró, a través de la construcción del indicador de pertinencia en el mercado laboral, diseñado a partir de seis variables que caracterizan a dicho mercado, que existe gran heterogeneidad en cuanto a la situación laboral para los egresados de cada una de las carreras. En términos generales, con buen mercado laboral destacan carreras del área de Ingeniería y Tecnología, así como algunas carreras del área de Ciencias Biológicas y de la Salud. En una situación intermedia se ubican las tradicionales carreras del área Económica-Administrativa y con inadecuado mercado laboral se encuentran carreras de las áreas de Ciencias Sociales y de Humanidades (BURGOS FLORES; LÓPEZ MONTES, 2010).

En el estudio de González Pérez y González Franco (2015), la mayoría de los egresados de contaduría del Centro Universitario de Los Altos obtuvieron trabajo y ascendieron dentro de su área de formación profesional. En el mismo Centro Universitario se realizó un estudio con egresados de la carrera de psicología, y los resultados mostraron que las áreas de desempeño de los entrevistados se circunscriben en su mayoría a la Psicología clínica y la Psicología educativa, aunque un alto porcentaje de psicólogos laboraban en áreas distintas a su formación (GONZÁLEZ ANAYA; CARRILLO TORRES, 2016). Los mismos investigadores reportan que entre los egresados de psicología $4.54 \%$ manifestaron no estar trabajando, 40.9\% laboran en actividades que no están relacionadas con la psicología, o donde no aplican los conocimientos adquiridos en su formación universitaria, mientras que el restante 54\% sí lo hace (GONZÁLEZ ANAYA; CARRILLO TORRES, 2016).

Resultados similares arrojó la investigación de Rubio Hernández y Salgado Vega (2014), realizada con egresados de la licenciatura de economía de la Universidad Autónoma del Estado de México (UAEMEX) del periodo 2000-2010. De acuerdo con este estudio los egresados presentan un comportamiento de buena aceptación respecto al proceso de transición al mercado laboral; sin embargo, son contratados en empleos que no corresponden a su formación y con baja remuneración.

Un tercer estudio realizado en el Centro Universitario de Los Altos por Pérez Pulido, Moreno García y Caldera Montes (2011), con una muestra de 405 egresados de un total de 1,872 alumnos que terminaron sus estudios durante los ciclos 2001 y 2007 (de alguna de las 13 carreras que se imparten en el campus), encontró que en la mayoría de las carreras los hombres han encontrado un mejor posicionamiento laboral en comparación con las mujeres, pues ellos cuentan con mejores puestos de trabajo y son mejor remunerados. El promedio de 
ingresos mensuales de los varones es de $8,731.00$ pesos, mientras que las mujeres perciben $6,457.00$ pesos. Esto representa una diferencia mensual de 2,274.00 pesos a favor de ellos. Sin embargo al comparar el ingreso promedio mensual por género y licenciatura, destaca que únicamente en tres carreras (Odontología, Veterinaria y Psicología) las mujeres están mejor remuneradas que los hombres.

Estos resultados coinciden con lo observado por Jiménez Vázquez (2011) en su revisión de los estudios sobre trayectorias laborales. La autora señala que las condiciones laborales de quienes egresan de la licenciatura son diferentes para hombres y mujeres: las mujeres tienen que esforzarse más para desarrollar una trayectoria exitosa en comparación con los hombres, y esto no siempre es reconocido en el aspecto social, laboral y económico, pues el mercado de trabajo está segmentado y estratificado (JIMÉNEZ VÁSQUEZ, 2011, p. $10)$.

Otro estudio que muestra las diferencias en las condiciones laborales entre hombres y mujeres es el realizado por Sánchez Olavarría (2012) con egresados de la carrera de comunicación en la Universidad del Altiplano (Tlaxcala). Los resultados de esta investigación permiten ver que la mayoría de los egresados de la carrera de ciencias de la comunicación han tenido escasa movilidad. No obstante, la movilidad ocupacional se presenta en mayor medida en los egresados con mayor tiempo en el mercado laboral, principalmente en las mujeres (SÁNCHEZ OLAVARRÍA, 2012).

Resultados similares han sido reportados por De Vries, Cabrera y Ríos (2013a), donde a partir de datos de egresados de nueve universidades mexicanas, descubrieron que los factores que explican mejor la diferenciación salarial son aspectos del mercado de trabajo mismo, el tipo de institución, el área de conocimiento, la experiencia laboral, el puesto del padre y el género. También identificaron diferencias salariales entre áreas de conocimiento: los puestos de altos ingresos se encuentran básicamente en los sectores económicoadministrativo (administración, economía) y técnico (ingenierías). En ambas áreas, los sueldos promedio son más altos.

Pero el ingreso al mercado de trabajo y las condiciones laborales no sólo tienen que ver con el origen socioeconómico y el sexo; hay factores estructurales, como el número de egresados y empleos en una ciudad o región, como lo indica el estudio de Segundo Ramírez (2009), que buscó encontrar de qué manera la política de diversificación que ha llevado a cabo la Universidad Autónoma de Ciudad Juárez (UACJ) ha repercutido en el tiempo que tardan sus estudiantes en encontrar empleo al término de sus estudios de nivel licenciatura, así como el ingreso que ellos perciben en su empleo después de dos años de egreso. Para ello utilizó la información del Seguimiento de Egresados que ha realizado año con año la UACJ a los egresados en el periodo 2001-2004 y que fueron encuestados en los periodos 2003-2006. Los resultados de este trabajo muestran que la ampliación de la matrícula por parte de la UACJ en carreras que por tradición cuentan con baja concentración de demanda estudiantil no ha afectado el tiempo que tardan sus egresados en encontrar empleo, lo que indica que la diversificación de la matrícula no ha generado un efecto negativo en la incorporación de los egresados de la UACJ a la vida laboral. Por el contrario, cuando los egresados pertenecen a una carrera de baja concentración, tiene una menor probabilidad de contar con un ingreso mensual de más de 6 salarios mínimos; esto genera un efecto negativo en el bienestar del 
individuo, así como desigualdad entre individuos con los mismos años académicos (SEGUNDO RAMÍREZ, 2009).

El estudio de Salas Durazo y Murillo García (2013) realizado a partir de los datos de la ENOE generada por el Instituto Nacional de Estadística y Geografía (INEGI) durante el intervalo comprendido entre 2005 y 2012, también descubrieron algunos patrones estructurales en el mercado de trabajo de los jóvenes. Por ejemplo, encontraron que la educación juega un papel importante en el posicionamiento y en el ingreso de los jóvenes al mercado de trabajo, pues en los segmentos medio bajo y bajo no existe una tendencia generalizada a llevar a cabo estudios medio superiores y superiores. También identificaron que los jóvenes ocupados que no cuentan con estudios de al menos nivel medio superior se encuentran casados; mientras que sus contrapartes con estudios superiores se encuentran en su totalidad solteros. De acuerdo con los autores, en el estrato bajo los costos de oportunidad de estudiar son tan altos que las personas deciden incorporarse al sector productivo con la restricción de que su salario en el tiempo nunca igualará al salario de quien decidió prepararse académicamente. Por su parte, en el estrato alto parecieran existir las condiciones para que los jóvenes se preparen en el ámbito universitario sin la presión de tener que emplearse (SALAS DURAZO; MURILLO GARCÍA, 2013).

El mismo estudio reporta que el principal obstáculo que enfrentan las mujeres al incorporarse a la dinámica productiva es que en esencia el mercado laboral mexicano es masculino. De acuerdo con los autores el tipo de empleos a los que acceden las mujeres, es en los sectores de comercio y servicios personales, mientras que los hombres en actividades agrícolas, ganaderas, silvícolas y de caza y pesca; siendo el punto de convergencia los trabajadores industriales, artesanos y ayudantes. Sin embargo, en el sector de universitarios las brechas de salario o puestos se reducen sustancialmente (SALAS DURAZO; MURILLO GARCÍA, 2013). También de acuerdo con este análisis las mujeres que cuentan con estudios medio superiores o superiores disminuían drásticamente las brechas de género, ya que sus condiciones laborales (salario, puesto) estaban situadas por encima de los hombres. Sin embargo, es importante señalar que la mayoría de estas mujeres provenían de estratos económicos alto y medio alto.

Además del sexo y los contextos socioeconómicos, también el tipo de carrera afecta las condiciones laborales de quienes egresan. A partir de un estudio de egresados realizado en la Benemérita Universidad Autónoma de Puebla por De Vries, Cabrera y Queen (2008), observaron que todos los indicadores para los egresados de carreras tradicionales (como derecho o contaduría) son mejores en comparación con carreras científicas (como física o bilogía) o novedosas (como administración turística o relaciones internacionales). Los autores explican: el mercado laboral ofrece más lugares para egresados de carreras tradicionales que para los demás, con puestos claramente definidos. Los egresados de carreras novedosas se pueden enfrentar con un mercado donde su especialidad no existe, lo que les obligue a ocupar puestos que no coinciden con sus estudios. En el caso de las carreras científicas, es posible que este mercado siempre haya sido muy limitado.

Los resultados reportados por Sánchez Olavarría (2013) indican que las diferencias en el mercado laboral también se relacionan con el tipo de carrera estudiada y la región donde buscan trabajo los egresados. En su estudio con egresados de la licenciatura en comunicación de la Universidad del Altiplano (Tlaxcala), identificó que los comunicadores acceden al 
empleo por la vía relacional, que la obtención del título no es prioritaria al momento de solicitar empleo y que los principales problemas de ingreso al mercado laboral son la falta de experiencia y la saturación del campo de trabajo del comunicador. De acuerdo con el autor, la falta de vinculación entre la universidad y el mercado de trabajo orilla a los jóvenes al subempleo en condiciones precarias y vulnerables. En cuanto a la participación de las mujeres como fuerza laboral se ha incrementado por medio de la obtención de mejores puestos de trabajo, sin embargo, estos no se han sostenido debido a que priorizan su participación en actividades propias de la familia como la manutención de los hijos (SÁNCHEZ OLAVARRÍA, 2013).

Además de los factores antes descritos, el tiempo de egreso juega un papel importante en las condiciones laborales de los universitarios. De acuerdo con Sánchez Olavarría (2014), los profesionales de la comunicación de recién egreso tienden a buscar colocarse en espacios laborales acordes con su formación, pero conforme avanzan en su trayectoria esta tendencia decrece, debido a la dificultad de insertarse en el campo laboral, lo que los orilla a buscar alternativas que frecuentemente se ubican en los ámbitos indirectamente relacionados o no relacionados con su profesión. Pero el tiempo de experiencia no sólo afecta lo que hacen los egresados, sino también las condiciones en que trabajan. De Vries, Vázquez Cabrera y Ríos Treto (2013) identificaron que el ingreso es mejor conforme las personas cuentan con más experiencia.

En concreto, los estudios previos nos indican que hay más hombres que mujeres estudiando y egresando de las licenciaturas, que una buena parte los estudiantes trabajó durante su estancia en la universidad y que las condiciones laborales de quienes egresaron dependen del lugar donde se estudió, de la carrera cursada, del sexo de la persona y de la experiencia laboral.

\section{DESCRIPCIÓN DEL CASO Y METODOLOGÍA}

El CUVT es una de las unidades desconcentradas de la Universidad Autónoma del Estado de México (UAEMEX) fundado en el año 2000 como parte del plan maestro de desconcentración. El CUVT está instalado en la comunidad de Santo Domingo Aztacameca, que pertenece al municipio de Axapusco, ubicado al norte del Estado de México y que forma parte de la Zona Metropolitana del Valle de México (ZMVM) ${ }^{3}$. El municipio se caracteriza por no tener asentamientos urbanos, las localidades de Axapusco son pueblos y rancherías. Santo Domingo Aztacameca cuenta con 3,012 habitantes y está a 6.9 kilómetros de la cabecera municipal. En la Figura 1 se puede apreciar como Axapusco, el municipio donde se ubica del CUVT pertenece a un espacio periurbano.

\footnotetext{
${ }^{3}$ La ZMVM está conformada por las 16 delegaciones de la Ciudad de México (antes Distrito Federal), 59 municipios de la zona norte del Estado de México y un municipio del estado de Hidalgo.
} 


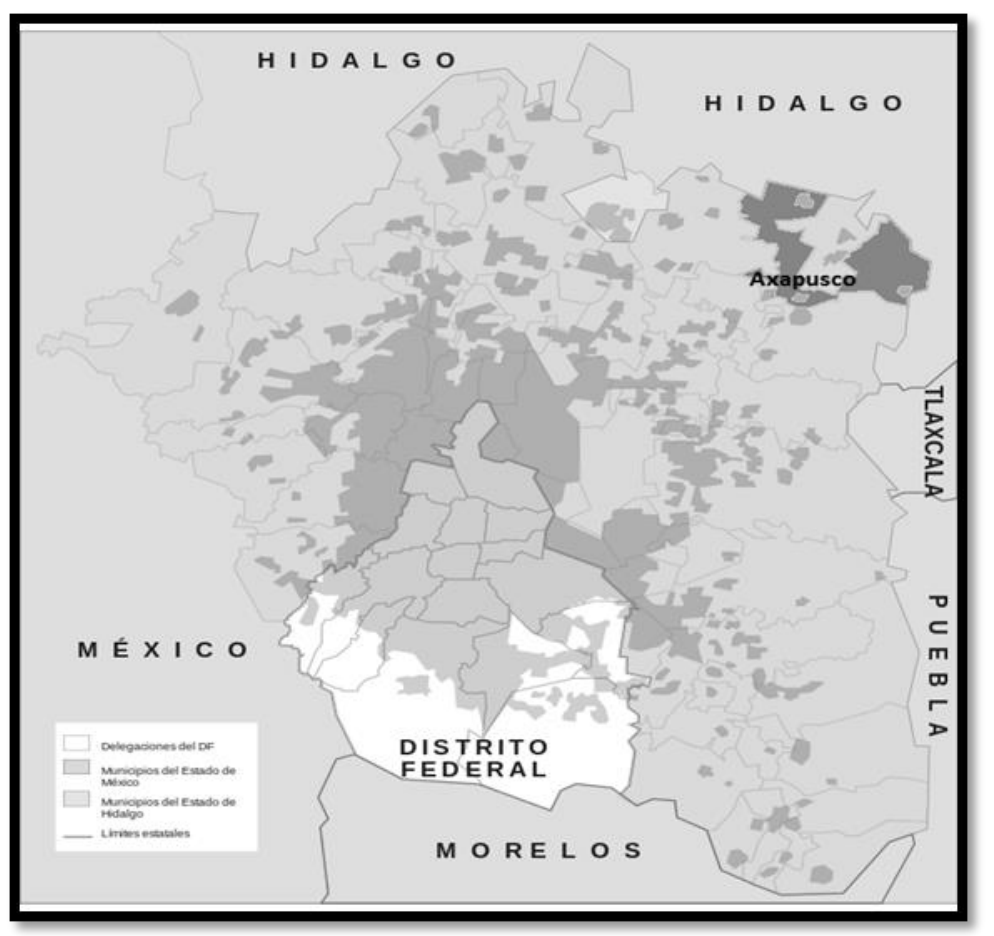

Figura 1. Ubicación del municipio de Axapusco en la Zona Metropolitana del Valle de México Fuente: Imagen tomada del sitio: http://goo.gl/0Htsh1

Simbología: Gris: Centros urbanos de la ZMVM.

El término periurbano se utiliza para caracterizar a una extensión continua de la ciudad que absorbe paulatinamente los espacios rurales circundantes y que, de acuerdo con De Mattos (2006), tiene la forma de un archipiélago. Como se puede apreciar en la Figura 1 la concentración de centros urbanos se desvanece conforme los municipios se alejan de la Ciudad de México, los centros urbanos cada vez son menos, más pequeños y se encuentran más alejados unos de otros. Esta disminución de centros urbanos implica menos población, y donde hay menos población hay menos acceso a oportunidades y servicios: empleo, educación, transporte.

La escuela inició con una matrícula de 140 alumnos y una planta docente de 18 profesores. Desde el 2012 el CUVT ofrece seis programas de licenciatura (Contaduría, Derecho, Informática Administrativa, Ingeniería en Computación, Psicología y Turismo), y contaba con una población estudiantil de 1,101 alumnos, de los cuales 738 recibían algún tipo de beca. Para ese mismo año el CUVT contaba con 83 profesores (14 de tiempo completo, 68 de asignatura y un técnico académico de tiempo completo) y 25 administrativos (un directivo, 10 de confianza y 14 sindicalizados) (UAEMEX, 2015). El área de influencia del CUVT abarca 21 municpios: 16 del Estado de México y cinco de Hidalgo, como se puede apreciar en la Figura 2. De los 3,848 estudiantes que habían ingresado al Centro hasta el ciclo 20142015 , el $54.4 \%$ son mujeres y el $45.6 \%$ son hombres. 


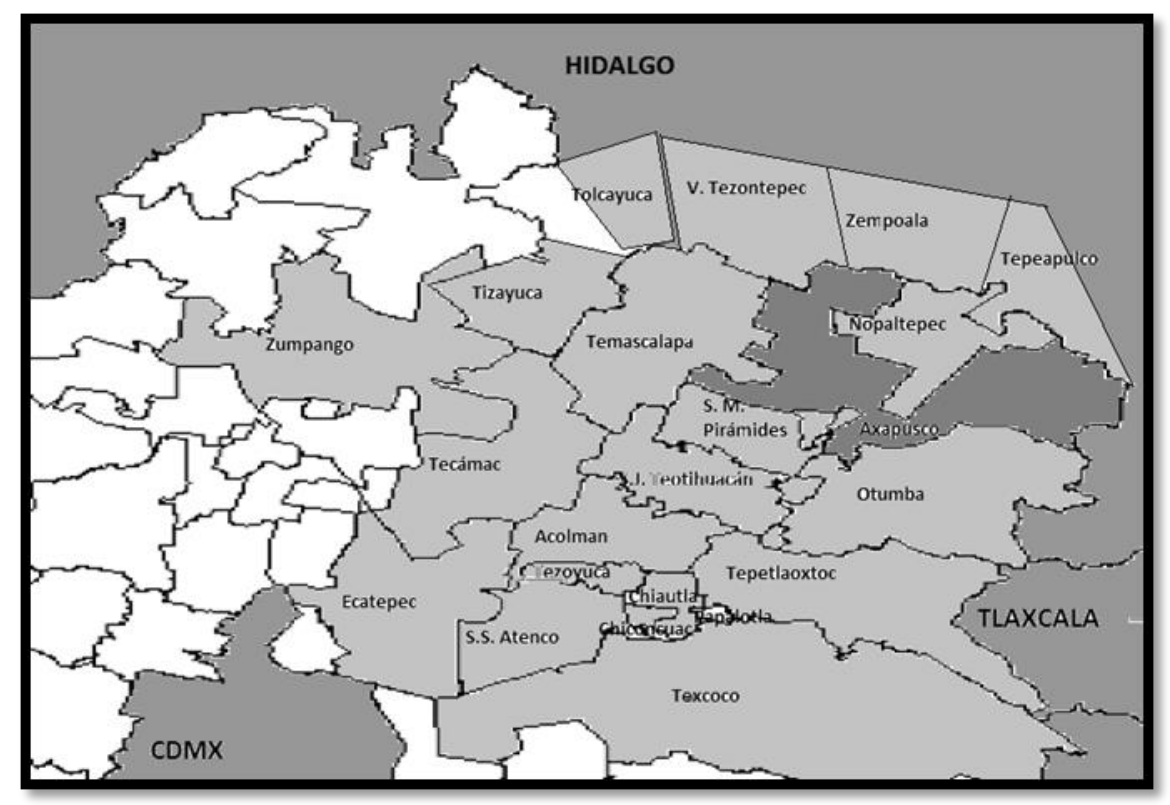

Figura 2. Elaboración propia a partir de INEGI, Marco Geoestadístico Municipal, 2005. Fuente: Basado en datos del CUVT, Departamento de Servicios Escolares.

La información que se presenta en este reporte se generó a partir de los datos ofrecidos por el Sistema Institucional de Seguimiento de Egresados (SISE) de la UAEMEX. Este sistema funcionó en su primera versión hasta el 2013. Actualmente funciona una nueva versión la cual sólo permite recuperar información de los ciclos 2014-2015 y 2015-2016, es por esta razón que se decidió trabajar con los datos que el sistema generó hasta 2013, pues la nueva versión genera información que en algunos casos no puede compararse con los datos previamente recopilados. El SISE aplicaba un cuestionario de 127 reactivos, de los cuales se recuperó la información que describe la situación socioeconómica de los encuestados. En particular se trabajó con los reactivos sobre la situación laboral y la dependencia económica en dos momentos: durante la licenciatura y al término de los estudios.

El análisis de los datos generados por el SISE tiene un enfoque cercano a la encuesta longitudinal retrospectiva, un recurso técnico de análisis de datos que permite establecer nexos entre períodos, propuesta por Casal et al. (2006). Esta propuesta parte de la idea de que los jóvenes están ubicados en el interior de una estratificación social y económica derivada de sus padres y que ésta configura delimitaciones en los campos de maniobra o de construcción de expectativas de posición social. Estos autores conciben a la juventud como un tramo de biografía, que se inicia con la pubertad y que tiende a concluir en la emancipación familiar plena, lo que implica vivir fuera de la casa paterna y ser independiente económicamente (CASAL et al., 2006).

La información que aquí se presenta es resultado de los reportes que el mismo sistema generaba con base en las respuestas al cuestionario que se aplica a los estudiantes cuando concluyen sus créditos y comienzan sus trámites de titulación. Este detalle es importante, pues el cuestionario difícilmente puede dar cuenta de qué pasa con las trayectorias laborales de los egresados, pues acaban de terminar sus estudios y muchos de ellos aún no trabajan. Otro detalle importante es que la versión anterior del SISE no permite consultar datos de 
identificación de los estudiantes, como el grado de escolaridad de los padres o el municipio en el que residen.

El número total de egresados registrados por el departamento de control escolar del CUVT hasta el 2013 fue de 2,106 de los cuáles 57.3\% son mujeres. Del total de egresados sólo 1,252 contestaron la encuesta del SISE. La edad promedio de los hombres es de $24.15 \mathrm{y}$ la de las mujeres 23.74. Aquí es importante señalar que la tasa de respuestas a los reactivos del SISE oscila entre 1,084 y 1,252, es por ello que al ver los totales, no siempre aparecen las mismas cantidades. Finalmente, dado que no se tiene acceso a los datos crudos, la información que en este apartado se muestra sólo tiene un carácter descriptivo.

A continuación se presentan los resultados del análisis de los datos recuperados del SISE, comparando la distribución de los egresados en dos momentos: mientras estudiaban la licenciatura y al término de sus estudios. Las variables con las que se realizó el análisis fueron: el tipo de bachillerato de procedencia, la posesión de auto, con quién vivían, de quién dependían económicamente, número de egresados que trabajan, relación del empleo con la carrera estudiada e ingresos por salarios mínimos.

\section{RESULTADOS. PROCESOS DE INDEPENDENCIA ECONÓMICA E INGRESO AL MERCADO LABORAL EN ESTUDIANTES Y EGRESADOS UNIVERSITARIOS}

Una característica común en casi todos los egresados es el tipo de escuela de educación media superior de la que provienen: de acuerdo con el SISE el 93\% provienen de escuela pública. Otra variable que puede arrojar luz sobre el nivel socioeconómico de los estudiantes y sus familias es la posesión de auto. Los datos del SISE indican que mientras estudiaban, sólo el 5\% de los egresados tenían auto y sólo el 3\% al egreso. Esta información sugiere que casi la totalidad de los egresados proviene de familias de clase media o baja.

El primer aspecto a comparar es con quién vivían los egresados mientras estudiaban y con quién vivían al egresar. En la Tabla 1 se observa que el $90 \%$ vivía con sus padres y sólo un porcentaje pequeño vivía con la o el cónyuge o con familiares.

Tabla 1. Con quién vivían

\begin{tabular}{|c|c|c|c|c|}
\hline $\begin{array}{c}\text { ¿Con quién } \\
\text { vivía? }\end{array}$ & $\begin{array}{c}\text { Durante la } \\
\text { carrera }\end{array}$ & $\%$ & $\begin{array}{c}\begin{array}{c}\text { Al término de los } \\
\text { estudios }\end{array} \\
\end{array}$ & $\%$ \\
\hline Padres & 1,145 & 91.4 & 961 & 81.2 \\
\hline $\begin{array}{l}\text { Hermanos } \\
\text { Familiares }\end{array}$ & $\begin{array}{l}14 \\
39\end{array}$ & $\begin{array}{l}1.1 \\
3.1\end{array}$ & $\begin{array}{l}18 \\
38\end{array}$ & $\begin{array}{l}1.5 \\
3.2\end{array}$ \\
\hline Cónyuge & 48 & 3.8 & 144 & 12.6 \\
\hline Solo & 5 & 0.3 & 22 & 1.8 \\
\hline Amigos & 1 & 0.0 & 0 & 0.0 \\
\hline Totales & 1,252 & 99.7 & 1,183 & 100.3 \\
\hline
\end{tabular}

Fuente: Elaboración propia a partir de datos tomados del "Sistema Institucional de Seguimiento de Egresados", UAEMEX, 2013.

En la Tabla 1 se puede se puede ver que la distribución cambió al término de los estudios, a pesar de que aún la mayoría vive con los padres, un $12 \%$ ya vive en pareja y un $2 \%$ vive solo. Estas diferencias pueden sugerir que el estudio de la carrera implica procesos

\begin{tabular}{l|l|l|l|l|l|l} 
(C) Rev. Inter. Educ. Sup. & Campinas, SP & v.3 & n.1 & p.66-89 & jan./abr. 2017 & ISSN 2446-9424 \\
\hline
\end{tabular}


de independencia respecto a la familia, ya sea a través de la relación de pareja o de la vida individual.

El siguiente aspecto analizado es la dependencia económica de los egresados mientras estudiaban y al término de los créditos. En este caso se muestran dos análisis, uno general y otro por carrera y género. Para la dependencia económica se hizo este análisis porque los datos muestran diferencias entre los grupos. En la Tabla 2 se puede ver que un $82 \%$ dependía económicamente de sus padres, $9 \%$ de sí mismo y $4 \%$ de la beca.

Tabla 2. De quién dependían económicamente los egresados

\begin{tabular}{c|c|c|c|c}
\hline $\begin{array}{c}\text { ¿De quién dependías } \\
\text { económicamente? }\end{array}$ & $\begin{array}{c}\text { Mientras } \\
\text { estudiaban }\end{array}$ & \% & $\begin{array}{c}\text { Al término de los } \\
\text { estudios }\end{array}$ & \% \\
\hline De mí mismo & 113 & 9.0 & 396 & 33.8 \\
De mis padres & 1,025 & 82.1 & 646 & 55.2 \\
De hermanos & 15 & 1.2 & 12 & 1.0 \\
De familiares & 17 & 1.3 & 15 & 1.2 \\
De mi cónyuge & 26 & 2.0 & 100 & 8.5 \\
De beca & 51 & 4.0 & 0 & 0.0 \\
\hline Total & 1,247 & 99.6 & 1,169 & 99.7 \\
\hline
\end{tabular}

Fuente: Elaboración propia a partir de datos tomados del "Sistema Institucional de Seguimiento de Egresados", UAEMEX, 2013.

Al término de los estudios se notan algunos cambios, como lo muestra la Tabla 2 donde la dependencia de los padres disminuye un $26.9 \%$, el porcentaje de quienes se mantienen a sí mismos aumenta un $24.8 \%$ y quienes depende de la o el cónyuge alcanza un 8.5\%. Si sumamos un $33.8 \%$ de quienes son autosuficientes más un $8.5 \%$ de quienes dependen del o la cónyuge, se puede ver que un poco más del $40 \%$ son independientes económicamente de los padres. Estos datos refuerzan la idea antes planteada, de que el tránsito por la universidad, en tres de cada 10 egresados, también implica un proceso de independencia económica de la familia, ya sea en pareja o de forma individual. En la Tabla 2 también destaca que algunos dependían económicamente de la beca: 51 casos, lo que representaba el $4 \%$ del total.

Sin embargo, ¿hay diferencias entre carreras y entre género? En la Figura 3, Gráfico "A", se puede ver que mientras estudiaban las diferencias por carrera y género casi son imperceptibles, casi todos dependen de los padres. 


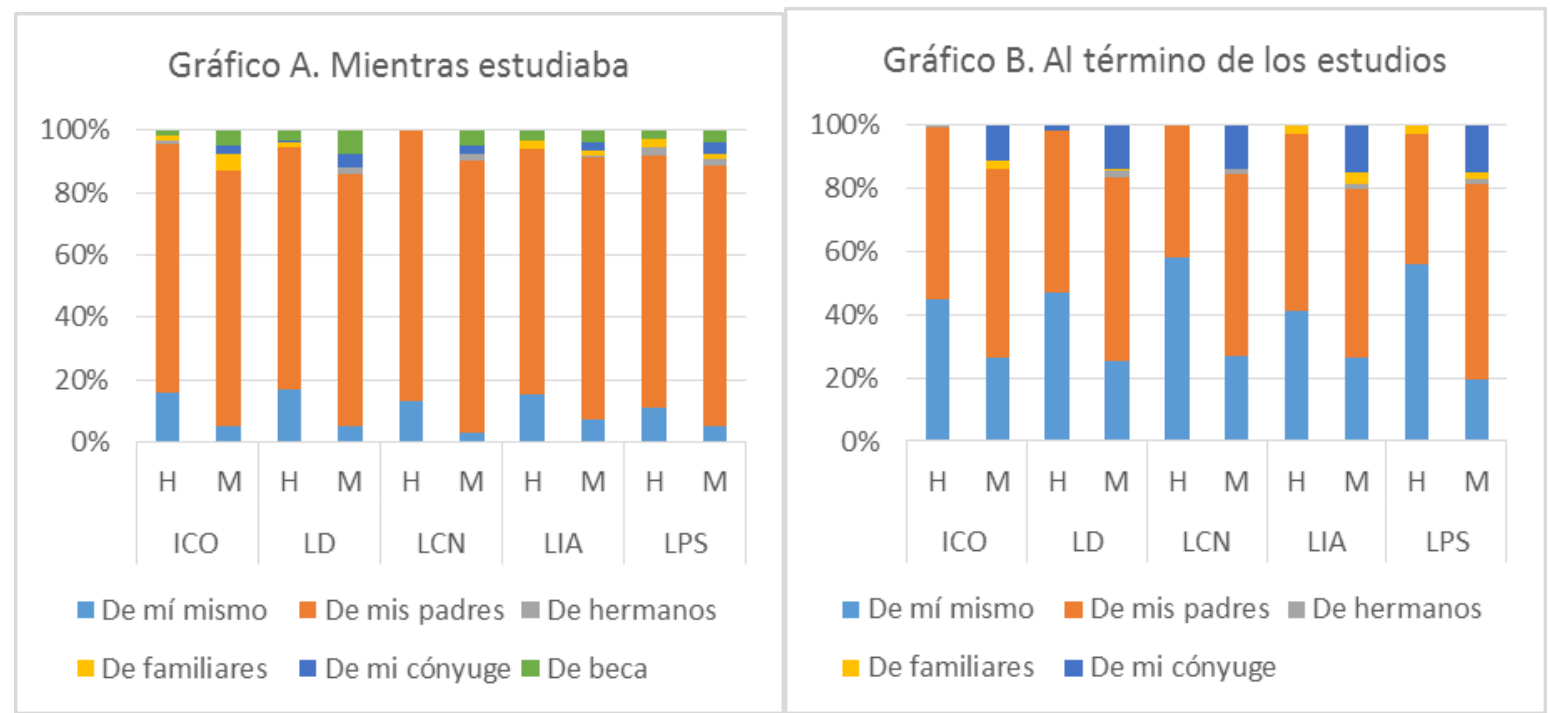

Figura 3. Dependencia económica de los egresados por carrera y género

Fuente: Elaboración propia a partir de datos del Sistema Institucional de Seguimiento de Egresados (UAEMEX, 2013). Carreras: ICO-Ingeniería en Computación; LD-Derecho; LCN-Contaduría; LIA-Informática Administrativa; LPS-Psicología. Sexo: H-Hombre; M-Mujer. Gráfico A, N=1,247; Gráfico B, $\mathrm{N}=1,169$.

Sin embargo, el panorama cambia al término de los estudios: en todos los casos aumenta el porcentaje de personas que dependen de sí mismas y en todas las carreras el porcentaje de hombres que ya no dependen de sus padres es mayor que en las mujeres, incluso en las carreras donde hay más mujeres que hombres, como en Psicología donde un $85 \%$ son mujeres.

Otro dato que llama la atención es que el número de mujeres que dependen económicamente del cónyuge aumentó en todos los casos, pero a pesar de eso, en todas las carreras el porcentaje de mujeres que es autosuficiente aumentó, además las mujeres que son autosuficientes son más que las que dependen de su cónyuge (Figura 3, Gráfico B). Finalmente, en la Figura 1 Gráfico "B" se puede observar que al término de los estudios, en las carreras de Contaduría y Psicología, los hombres que son autosuficientes económicamente son más que aquellos que dependen de sus padres, y que en Ingeniería en Computación y Derecho, las cifras se distribuyen casi a la mitad. El único caso que muestra diferencias más marcadas entre quienes dependen de los padres y de sí mismos es Informática Administrativa, donde un 55\% aún depende de los padres y un 37\% depende de sí mismo. Estas cifras quizá indican que hay un ingreso diferenciado al mercado laboral por carrera y por sexo.

El siguiente punto a analizar es el número de egresados que trabajaban mientras acudían a la universidad y al término de los estudios. Los datos del SISE indican que el porcentaje de egresados que trabajaba durante los estudios era de un 30\% (480 personas) y un $41 \%$ cuando salió de la escuela, pero al igual que en la dependencia económica, las cifras muestran diferencias por carrera y género, como lo muestra la Figura 4. 


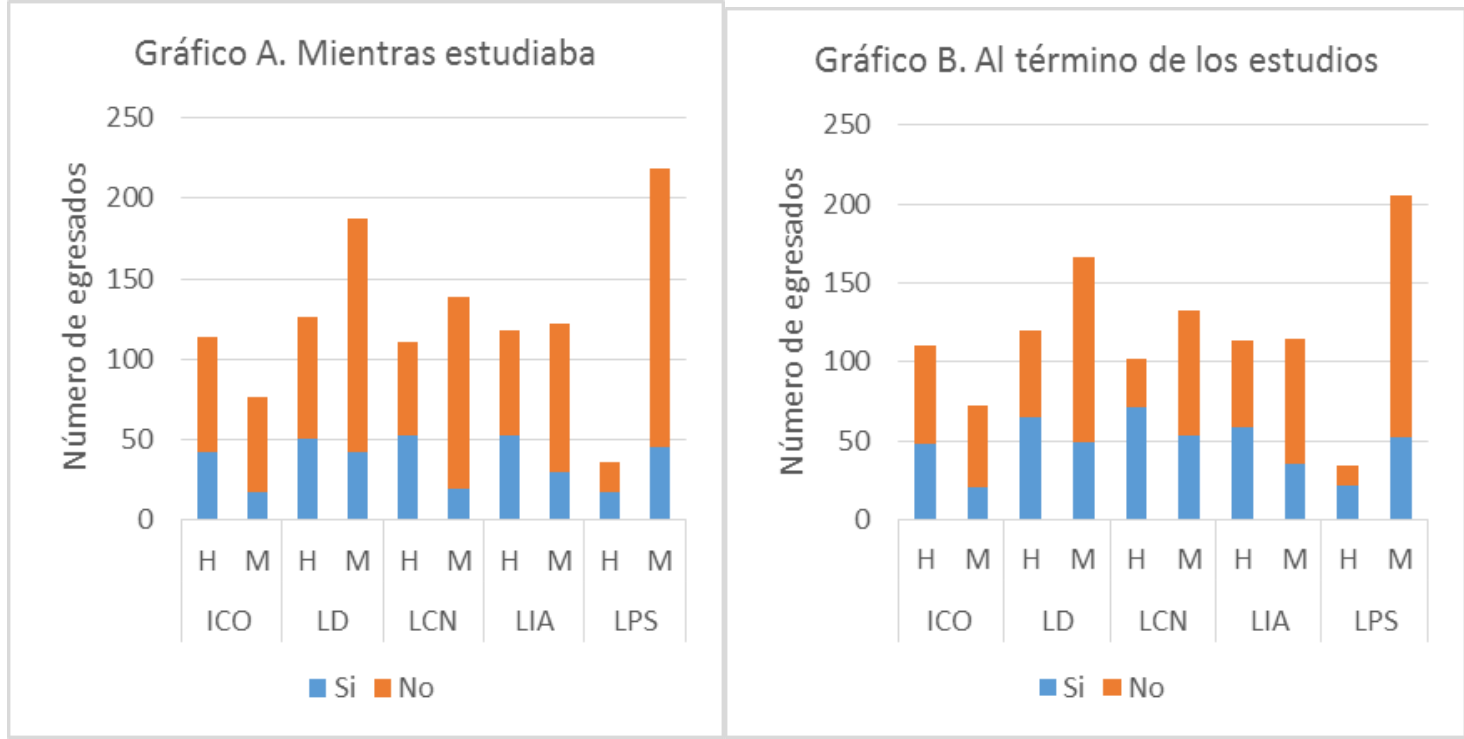

Figura 4. Distribución de quienes trabajaban por carrera y género

Fuente: Elaboración propia a partir de datos tomados del "Sistema Institucional de Seguimiento de Egresados", UAEMEX, 2013. Gráfico A, N=1,170; Gráfico B, N=1,247.

Una de las primeras cosas que se puede ver son las diferencias por género, donde en todos los casos el número de hombres que trabajó mientras estudiaba es mayor que el porcentaje de mujeres. Estos datos coinciden con lo reportado por Solís y Blanco (2014) en jóvenes en la Ciudad de México, donde observaron un ingreso más temprano al mercado de trabajo por parte de los hombres en comparación con las mujeres. Otro dato que resalta son los casos de Contaduría e Informática Administrativa, donde casi la mitad de los hombres trabajó durante sus estudios universitarios.

En la Figura 4, Gráfica "B", se puede ver que las cifras cambian al término de los estudios, en todos los casos, tanto en hombres como mujeres, aumenta la frecuencia de quienes trabajaban. Estos datos pueden reforzar la idea de que los estudios universitarios contribuyen a la independencia económica de los hijos, aunque al igual que cuando estudiaban, es mayor el número de los hombres que trabajaban en relación con las mujeres. Otro dato que llama la atención es que a pesar de que en cuatro de las cinco carreras hay más egresadas que egresados, el número de hombres que reportó trabajar al término de los estudios es mayor al de las mujeres: 265 hombres y 210 mujeres.

La pregunta obvia al mirar estos datos es: ¿dónde trabajan los egresados? Los datos arrojados por el SISE no permiten responder con precisión a esta pregunta, pero sí indican que de las 480 personas que respondieron haber estado trabajando al egreso, el 66\% contestó que tiene un empleo que se relaciona con la carrera que estudió. Al igual que en los datos previos, estas cifras generales muestran diferencias por carrera y género como se puede ver en la Figura 5. 


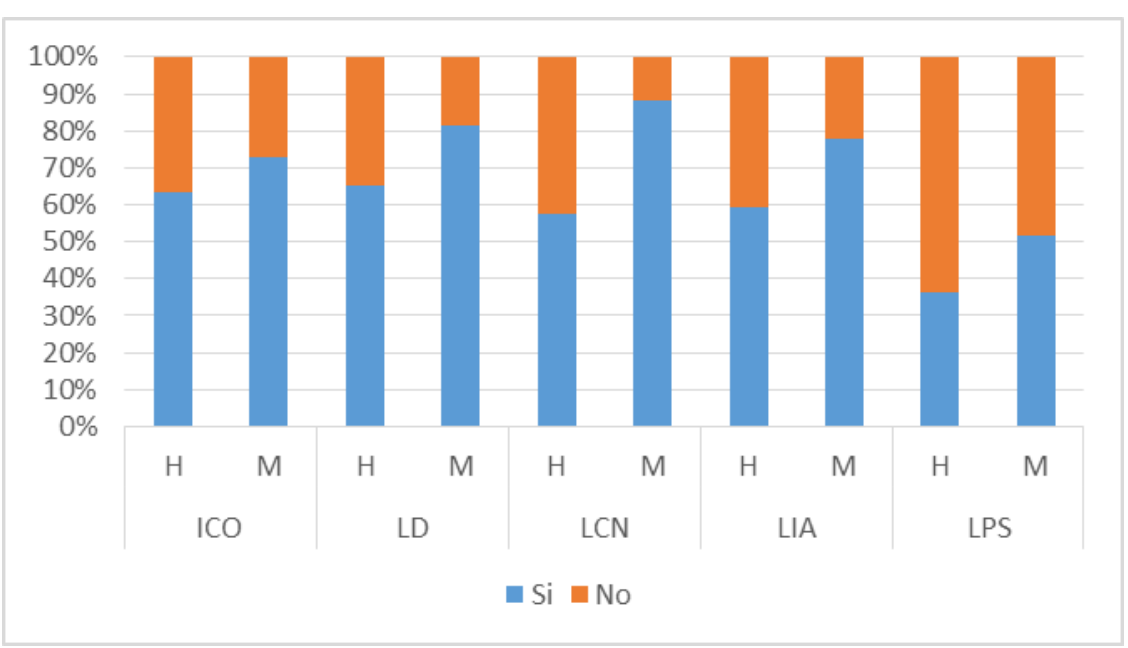

Figura 5. Relación del empleo con los estudios por carrera y sexo

Fuente: Elaboración propia a partir de datos tomados del "Sistema Institucional de Seguimiento de Egresados", UAEMEX, 2013. $\mathrm{N}=480$.

Una de las primeras cifras que llaman la atención es que, a pesar de que hay más egresados que trabajan, la gran mayoría de las egresadas de Derecho, Contaduría e Informática Administrativa tiene un empleo relacionado con sus estudios universitarios. Quizá estos datos indican que las mujeres tienen más probabilidad de ejercer un empleo relacionado con su carrera que los hombres.

En particular resaltan los casos de Contaduría y Derecho, donde a pesar de que hay menor número de mujeres egresadas que reportaron trabajar, el porcentaje de ellas que ejerce su carrera rebasa al de los hombres. De nuevo los datos muestran un ingreso al mercado laboral, en este caso al mercado laboral relacionado con los estudios cursados, diferenciado por género y carrera. En resumen, lo que estos datos sugieren es que en general los hombres inician su vida laboral antes que las mujeres, pero que las mujeres tienen más probabilidad de conseguir un empleo relacionado con su carrera al término de sus estudios.

En lo que respecta a los ingresos, la mayoría de los egresados (39\%) gana entre tres y cinco salarios mínimos; el $20 \%$ percibe entre cinco y diez salarios; el $10 \%$ entre 10 y 15; el $18 \%$ menos de tres; el $7 \%$ entre 15 y 20; y el $6 \%$ entre gana más de 20 salarios mínimos. En general las diferencias entre los ingresos de hombres y mujeres no son muy marcadas, sin embargo los mejores ingresos para los varones muestran ligeras diferencias en los rangos de salarios más altos. Para cerrar este apartado se muestra en la Figura 3 la distribución de quienes egresaron del CUVT por el número de salarios mínimos, sexo y carrera. 


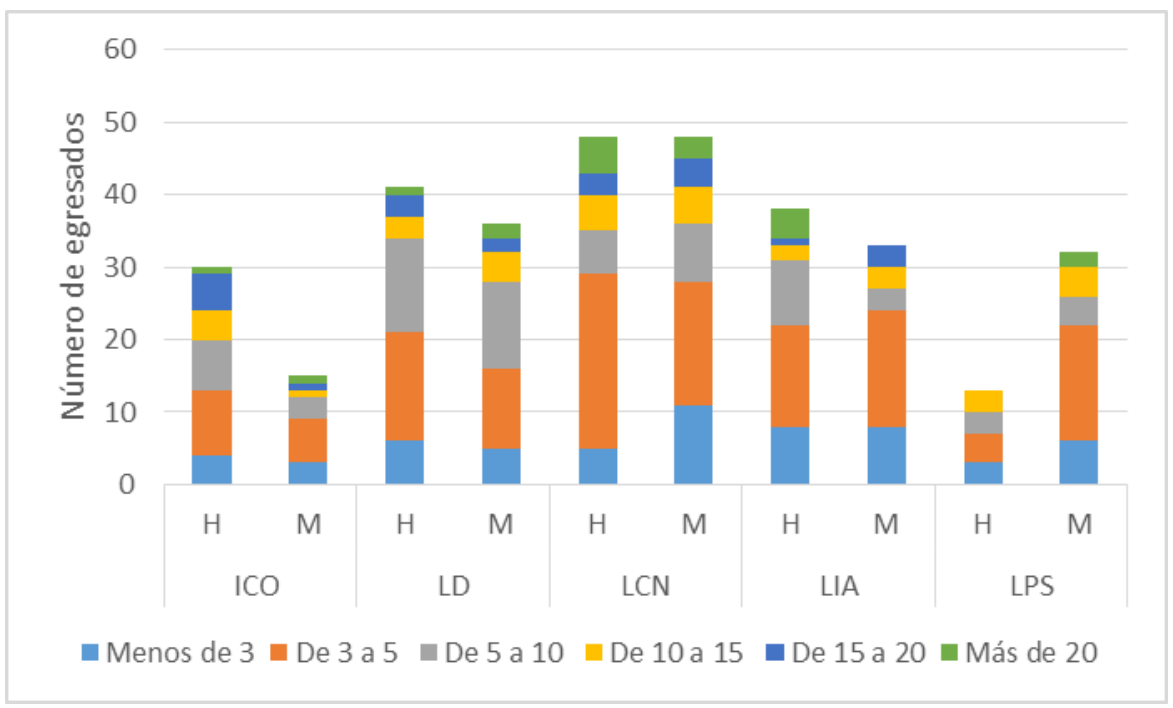

Figura 6. Distribución por número de salarios mínimos por sexo y carrera

Fuente: Elaboración propia a partir de datos tomados del "Sistema Institucional de Seguimiento de Egresados", UAEMEX, 2013. N=334.

La Figura 6 muestra que en tres carreras hay más hombres que mujeres trabajando: ICO, LDE y LIA. En Contaduría el número de hombres y mujeres es el mismo, y en Psicología, dado que hay un mayor número de mujeres, el número de ellas que trabajan es mayor al de los hombres. En lo que respecta al número de salarios percibidos, sólo en los casos de Contaduría y Psicología hay más mujeres que hombres con menos de tres salarios; la mayoría, en todas las carreras, se encuentra en el rango de tres a cinco salarios. La distribución de egresados y egresadas en los rangos de mayores ingresos no presenta una tendencia clara. Por último, llama la atención el caso de Contaduría, en el que la distribución por sexo es muy similar, tanto en el número de egresados como en la manera como se distribuyen entre los distintos rangos de ingreso.

Con esta información se cierra el apartado de descripción de los resultados, que en general nos muestra que quienes egresaron del CUVT provienen de familias de nivel socioeconómico medio y bajo y que a su paso por los estudios universitarios han conseguido cierta independencia económica de los padres. Además los datos sugieren un ingreso al mercado de trabajo diferenciado por carrera y sexo.

\section{CONCLUSIONES Y ALGUNAS HIPÓTESIS}

El principal objetivo de este trabajo fue describir las condiciones socioeconómicas y laborales de los egresados del CUVT, durante los estudios y al término de los mismos, con el fin de generar algunas hipótesis acerca de los procesos de independencia familiar que se dan en este periodo. Sin embargo, a lo largo del análisis se encontraron datos que sugieren ciertas tendencias diferenciadas por sexo y carrera, en lo que refiere al término de los estudios y las condiciones laborales. Es por ello que en este apartado se discuten en primer lugar estas tendencias encontradas, para después regresar a las hipótesis sobre los procesos de independencia económica. 
En lo que refiere al ingreso al mercado laboral, el análisis indicó que hubo más hombres que mujeres que trabajaban durante la carrera. Esta tendencia permanece al término de la licenciatura donde a pesar de que hay más mujeres que hombres (tanto al ingreso como al egreso), el número de hombres que reportó trabajar es mayor en todas las carreras (a excepción de Psicología). Lo cual sugiere que los hombres ingresan al mercado laboral antes que las mujeres y que tienen más probabilidades de encontrar empleo al término de la universidad. Además los datos indican que la mayoría de los encuestados fueron dependientes económicos de sus padres mientras estudiaban y continuaban siéndolo al término de la universidad.

Algunas de estas tendencias contrastan con los resultados de las investigaciones revisadas, por ejemplo el estudio realizado por Planas Coll (2013) en el que la mayoría de los estudiantes trabajó mientras acudía a la universidad. Otro estudio que muestra resultados distintos es el realizado en el CU Los Altos donde la mayoría de los egresados de la carrera de Contaduría realizó un trabajo que les permitió ser autosuficientes económicamente mientras estudiaban (GONZÁLEZ PÉREZ; GONZÁLEZ FRANCO, 2015). Algo distinto ocurrió con quienes egresaron de psicología de la misma institución, donde sólo el 16\% logró tener independencia económica durante la licenciatura (GONZÁLEZ ANAYA; CARRILLO TORRES, 2016).

Las diferencias en las condiciones laborales también se ven en el salario. Aunque las diferencias entre hombres y mujeres encontradas en el análisis no son muy marcadas, la tendencia es que haya más hombres en los rangos de salarios altos y más mujeres en los rangos de salarios bajos. Las investigaciones revisadas indican que las condiciones laborales de quienes egresan de la licenciatura no sólo presentan diferencias entre carreras, también entre sexos, en promedio los hombres ganan más que las mujeres, pero no ocurre lo mismo en todas las carreras (PÉREZ PULIDO; MORENO GARCÍA; CALDERA MONTES, 2011). Además algunos estudios indican que el mayor tiempo de experiencia laboral puede mejorar las condiciones de trabajo de las mujeres (PLANAS COLL; ENCISO ÁVILA, 2013; SÁNCHEZ OLAVARRÍA, 2012).

Una posible explicación a estas diferencias es la que ofrece Corbett (2005), que señala que la importancia de las credenciales educativas cambia entre hombres y mujeres, de tal forma que para las mujeres la educación formal es la única ocupación en un mercado diseñado para los hombres, y el pasaporte para salir de la región. De acuerdo con este autor hay un ingreso diferenciado al mercado laboral por género: los hombres que se quedan en la región suelen ocuparse en empleos que requieren baja capacitación; en cambio las mujeres que no salen de la región trabajan en puestos que exigen un mínimo de credenciales educativas (cajeras o empleadas).

Pero además las condiciones laborales parecen también determinar los procesos de independencia económica y familiar. Es cierto que para cuando los estudiantes terminaron la carrera el número de quienes dependían económicamente de sus padres disminuyó, pero los procesos fueron distintos para hombres y mujeres. Mientras que sólo dos hombres dependían económicamente de su pareja, 98 mujeres estaban en la misma situación. Además si comparamos el número de quienes son autosuficientes financieramente, se puede identificar que mientras 5 de cada 10 hombres son autosuficientes, sólo 2 de cada 10 lo son en el grupo de mujeres. Sin embargo, las cifras también muestran que hay más egresadas que dependen 
económicamente de sí mismas en comparación con aquellas que dependen de su cónyuge: el $67 \%$ de las mujeres que no depende económicamente de sus padres son autosuficientes.

En lo que refiere a la dependencia económica de quienes egresaron del CUVT contrastan un poco con el dato de con quién viven, pues aunque el porcentaje de quien dependía financieramente de sus padres disminuyó, aun la gran mayoría sigue viviendo con ellos (el 81\%). Lo que este dato puede indicar es que a lo largo de la licenciatura los estudiantes se hicieron más independientes económicamente de sus padres, pero que aún dependen de ellos, incluso aquellos que han formado una nueva familia. En la variable de quien vive solo, el cambio en términos porcentuales no parece muy grande, pues pasó del $1 \%$ al $2 \%$.

Aunque en general la mayoría de quienes reportaron estar trabajando al término de sus estudios lo hacían en alguna actividad relacionada con la licenciatura cursada, hay algunas diferencias por carrera. Por ejemplo, en la carrera de Contaduría casi el $90 \%$ trabaja en algo relacionado con los estudios. Algo similar pasa en Derecho e Informática Administrativa, donde alrededor del $80 \%$ ejerce su profesión. El único caso que no presenta esta tendencia es Psicología, pues sólo un poco más de la mitad trabaja en algo relacionado con su profesión.

Estos resultados contrastan con los obtenidos en otros estudios donde los análisis indican que los egresados pueden conseguir empleos mal remunerados y no relacionados con sus estudios universitarios (GONZÁLEZ ANAYA; CARRILLO TORRES, 2016, RUBIO HERNÁNDEZ; SALGADO VEGA, 2014, BURGOS FLORES; LÓPEZ MONTES, 2010), aunque en el caso de los egresados de Contaduría del CU Los Altos, la mayoría encontró puestos relacionados con la licenciatura que estudiaron (GONZÁLEZ PÉREZ; GONZÁLEZ FRANCO, 2015), lo cual coincide con lo hallado en el presente estudio.

Estas conclusiones parciales se ajustan a lo propuesto por De Vries y Navarro (2011), a partir de los datos del proyecto Proflex: hay problemas de desempleo, pero la inserción exitosa (medida en términos de empleo y de sueldo) es el resultado de una complicada interacción entre el desarrollo de la economía, el área de conocimiento, el tipo de institución (privada-pública), el género y el pasado familiar.

Para finalizar y con base en lo que indican los estudios previos y el análisis realizado para este documento se sugieren algunas hipótesis:

- Hay una forma diferenciada de ingreso al mercado laboral por sexo. Quienes más se benefician de esta diferenciación son los hombres, pues inician primero su experiencia laboral y suelen ser favorecidos con mejores salarios. Esta afirmación aplica tanto para estudiantes como egresados. En coincidencia con lo que propone Sendón (2013), se puede decir que la democratización educativa para las mujeres está mucho más lograda que su incorporación igualitaria al sistema productivo. La escuela, aunque a largo plazo puede tener un poder transformador determinante, y ser un espacio donde se transita aparentemente de manera igualitaria, siempre y cuando la igualdad no se traduzca en los ingresos o en las posiciones más importantes en el mundo laboral. El sistema ha cedido a la demanda de mayor acceso a la educación, siempre cuando esta 
acumulación de niveles educativos no surtan los mismos efectos para todos en el campo productivo (SENDÓN, 2013, p. 26).

- Hay una diferenciación en el ingreso al mercado laboral por carrera, quienes estudian carreras tradicionales, como Derecho y Contaduría (en el caso del CUVT), suelen tener mejores condiciones laborales. De Vries, Cabrera y Queen (2008) sugieren: los egresados de carreras tradicionales tienen más posibilidades de encontrar trabajo en el sector público y si se considera que el sector público consta básicamente de tres subsectores (educación, salud y la burocracia estatal), es de esperar que este mercado sea más accesible para el grupo tradicional que para el sector novedoso. Además, las carreras relacionadas con la tecnología están más orientadas al sector privado y más sujeto a los vaivenes del mercado. Finalmente, el grupo tradicional tiene mayores posibilidades de asociarse a una pequeña empresa o abrir un despacho o consultorio, lo que les convierte en dueño o socio, o en profesionista independiente y quizá también por ello muestran tasas más altas de congruencia entre estudios y empleo.

- Estas formas diferenciadas de ingreso al mercado laboral pueden sugerir cierta coincidencia con lo hallado por Jiménez Vásquez (2011), la existencia de un mercado de trabajo segmentado y estratificado, en este caso por sexo y carrera.

- El paso de los jóvenes por la universidad puede contribuir a su proceso de independencia económica, pero este tránsito es especialmente importante para las mujeres, pues la mayoría de las que tienen un empleo al término de los estudios trabaja en actividades relacionadas con su carrera, lo cual no sería posible de no haber cursado estudios superiores. Además, la mayoría de las mujeres que reportaron no depender económicamente de sus padres y ser autosuficientes es mayor al número de quienes dependen del cónyuge. Quizá estos datos sugieran un proceso de empoderamiento por parte de las mujeres a partir de sus estudios universitarios, lo cual concuerda con algunos estudios previos (KAUSHIK, KAUSHIK; KAUSHIK, 2006).

- El proceso de independencia económica no siempre se da de forma conjunta con la independencia familiar, pues aunque aumentó el número de jóvenes que expresaron no depender económicamente de sus padres al término de los estudios, la mayoría aún vive con ellos. Esto puede indicar una fase en el proceso de independencia de los jóvenes respecto de sus familias, pues no hay que perder de vista que quienes contestaron el cuestionario del SISE acaban de terminar los créditos de la carrera. Siguiendo este orden de ideas, se esperaría que al paso del tiempo habría más egresadas y egresados independientes económicamente y que vivan fuera de la casa paterna, pues como proponen Casal et al. (2006), la emancipación familiar plena tiene una concreción en el acceso a una nueva vivienda, aunque hay muchas formas de concreción y también formas de regresión o retorno: hay emancipaciones intermedias donde los padres ayudan mucho económicamente y a veces continúan ejerciendo cierto control sobre espacios y tiempos; hay también retornos al hogar de origen después de un período más o menos largo de ejercicio de la emancipación. Algunas 
emancipaciones son muy diferidas y estos jóvenes prolongan el tiempo de residencia en casa de los padres. Una parte puede permanecer por mucho tiempo en casa de los padres (por ejemplo, bajo formas de soltería definitiva) e incluso no pasar por la emancipación domiciliar (CASAL et al., 2006, p.32-33).

En conclusión se puede decir que las formas diferenciadas de ingreso al mercado laboral por sexo y carrera, determinan procesos de independencia familiar distintos, donde los hombres tienen más probabilidades de ser autosuficientes económicamente y vivir fuera de la casa de los padres, que las mujeres. En los itinerarios, en los procesos de transición de la juventud a la adultez, hay una diversidad social que es explicada por su proximidad a la estructura social y la segmentación. Los itinerarios varían sustancialmente según historia, territorio y culturas (CASAL et al., 2006).

En un medio perirubano (con rasgos similares a los espacios rurales) donde el mercado de trabajo está diseñado para ser aprovechado prioritariamente por hombres con baja capacitación, los estudios superiores pueden funcionar como catalizador del proceso de independencia familiar, particularmente para las mujeres (CORBETT, 2005). El tener una licenciatura amplía las oportunidades de trabajo a las mujeres y con ello la probabilidad de recibir un ingreso suficiente para no depender de sus padres ni de algún hombre. Esta idea permite formular una última hipótesis: las personas que se pueden beneficiar más de una carrera universitaria son aquellas que tienen más desventajas sociales, en este caso concreto: las mujeres.

\section{REFERENCIAS}

BURGOS FLORES, Benjamín; LÓPEZ MONTES, Karla. La situación del mercado laboral de profesionistas. Revista de la Educación Superior, México, v. 39, n.4 [156], p.19-33, 2010 .

CARRILLO REGALADO, Salvador; RÍOS ALMODÓVAR, Jesús Gerardo. Oferta de trabajo de los estudiantes de la Universidad de Guadalajara y de México: un análisis comparativo. Perfiles Educativos, México, v.36, n.144, p.85-104, 2014.

CARRILLO REGALADO, Salvador; RÍOS ALMODÓVAR, Jesús Gerardo. La oferta de trabajo en los estudiantes de licenciatura en México. Revista de la Educación Superior México, v.38, n.3 [151], p.39-56, jul./sep. 2009

CASAL, Joaquim et al. Aportaciones teóricas y metodológicas a la sociología de la juventud desde la perspectiva de la transición. Papers: Revista de Sociología, Barcelona, n.79, p.2148, 2006.

CORBETT, Michael. Rural education and out-migration: the case of a coastal community.

Canadian Journal of Education, v.28, n.1/2, p. 52-72, 2005. 
CUEVAS DE LA GARZA, José Fernand; DE IBARROLA NICOLÍN, María. Vidas cruzadas Los estudiantes que trabajan: un análisis de sus aprendizajes. Revista de la Educación Superior, México, ANUIES, Vv.42, n.1 [165], p.125-148, ene./mar. 2013.

DE MATTOS, Carlos. Modernización capitalista y transformación metropolitana en América Latina: cinco tendencias constitutivas. In: GERAIGES DE LEMOS, A.; ARROYO, M.; SILVEIRA, M. Silveira, América Latina: cidade, campo e turismo. San Pablo: CLACSO, 2006. p. 7 41-773. Disponible en: <http://bibliotecavirtual.clacso.org.ar/ar/libros/edicion/ lemos/03mattos.pdf> Acceso: 26 de noviembre de 2015.

DE VRIES, Wieste; NAVARRO RANGEL, Yadira. ¿Estudias o trabajas? La aportación de la experiencia laboral durante los estudios. In: CONGRESO NACIONAL DE INVESTIGACIÓN EDUCATIVA, 13.: 2015, Chihuahua, México. Anais... Chihuahua, México: Consejo Mexicano de Investigación Educativa, 2015.

DE VRIES, Wieste, VÁZQUEZ CABRERA, Rebeca; RÍOS TRETO, David. Millonarios o malparados: ¿de qué depende el éxito de los egresados universitarios? Revista

Iberoamericana de Educación Superior, México, v.4, n.9, p. 3-20, 2013. Disponible en: www.redalyc.org/articulo.oa?id=299126789001. Acceso: 26 nov. 2015.

DE VRIES, Wietse; NAVARRO, Yadira. ¿Profesionistas del futuro o futuros taxistas? Los egresados universitarios y el mercado laboral en México. Revista Iberoamericana de Educación Superior, México, v.2, n.4, p. 3-27, 2011. Disponible en: <http://ries.universia.net/index.php/ries/article/view/71>. Acceso: 3 oct. 2016.

DE VRIES, Wieste et al. Conclusiones a contrapelo. La aportación de distintas carreras universitarias a la satisfacción en el empleo. Revista de la Educación Superior, México, v.37, n.2 [146], p. 67-84, abr./jun. 2008.

ENCISO ÁVILA, María Isabel. El origen social de los graduados y la equidad en el acceso a la universidad. Revista de la Educación Superior, México, v.42, n.1 [165], p. 11-29, ene./ mar. 2013.

GONZÁLEZ PÉREZ, Cándido y GONZÁLEZ FRANCO, Margarita. Puestos laborales de los egresados de la carrera de Contaduría Pública del Centro Universitario de los Alto. In: CONGRESO NACIONAL DE INVESTIGACIÓN EDUCATIVA, 13.:2015, Chihuahua, México. Anais... Chihuahua, México: Consejo Mexicano de Investigación Educativa, 2015.

GONZÁLEZ ANAYA, Ana Gabriela; CARRILLO TORRES, Paulo Alberto. Inserción laboral de los psicólogos egresados del Centro Universitario de Los Altos. Revista Iberoamericana para la Investigación y el Desarrollo Educativo, México, v.6, n.12, 2016.

JIMÉNEZ VÁSQUEZ, Josefina. Tendencias y hallazgos en los estudios de trayectoria: una opción metodológica para clasificar el desarrollo laboral. Revista Electrónica de

Investigación educativa. México, v.11, n.1, 2011. Disponible en: <http://redie.uabc.mx/vol11no1/contenido-jimenez.html>. Acceso: 6 jul. 2016.

KAUSHIK, Surendra; KAUSHIK, Shorav; KAUSHIK, Shobha. How higher education in rural India helps human rights and entrepreneurship. Journal of Asian Economics, n.17, p. 29-34, 2006. Disponible en: doi:10.1016/j.asieco.2006.01.004. Acceso: 6 abr. 2015.

\begin{tabular}{l|l|l} 
v.3 & n.1 & p.66-89
\end{tabular}


PÉREZ PULIDO, Ignacio; MORENO GARCÍA, Hugo; CALDERA MONTES, Juan FRANCISCO. Análisis de la situación laboral de los egresados del Centro Universitario de Los Altos. In: CONGRESO NACIONAL DE INVESTIGACIÓN EDUCATIVA, 10.: 2011, Veracruz, México. Anais... Veracruz, Mexico: Consejo Mexicano de Investigación Educativa, 2011.

PLANAS COLL, Jordi. Los itinerarios laborales de los universitarios y la calidad de su inserción profesional. Revista de la Educación Superior, México, v.1, n.16, p. 31-62, ene./ mar. 2013.

PLANAS-COLL, Jordi; ENCISO ÁVILA, Isabel-María. Los estudiantes que trabajan: ¿tiene valor profesional el trabajo durante los estudios? Revista Iberoamericana de Educación Superior, México, v.5, n.12, p. 23-45, 2014. Disponible em: <http://ries.universia.net/index.php/ries/article/view/322>. Acceso: 4 de octubre de 2016.

RUBIO-HERNÁNDEZ, Lisy; SALGADO VEGA, María Del Carmen. Características del proceso de transición al mercado laboral. Caso de los licenciados en economía del Estado de México, 2000-2010. CPU.e.: Revista de Investigación Educativa, México, n.19, p 28-59, 2014.

SALAS DURAZO, Iván Alejandro; MURILLO GARCÍA, Favio. Los profesionistas universitarios y el mercado laboral mexicano: convergencias y asimetrías. Revista de la Educación Superior, México, v.42, n.1 [165], p. 63-81, ene./mar. 2013.

SÁNCHEZ OLAVARRÍA, César. Los egresados de comunicación y el mercado laboral: un estudio de trayectorias profesionales. Revista Iberoamericana de Educación Superior, v.5, n.13, p. 40-54, 2014. Disponible en: http://ries.universia.net/index.php/ries/article/view/316. Acceso: 14 de octubre, 2016.

SÁNCHEZ OLAVARRÍA, César. La inserción laboral de los comunicadores de la Universidad del Altiplano. Revista de la Educación Superior, México, v.42, n.1 [165], p. 105-123, ene./mar. 2013.

SÁNCHEZ OLAVARRÍA, César. La movilidad profesional y generacional del comunicador de la Universidad del Altiplano. Revista Electrónica de Investigación educativa, México, v.14, n.2, p. 150-165, 2012. Disponible en: <http://redie.uabc.mx/vol14no2/contenidoschzolavarria2012.html >. Acceso: 14 ago. 2016.

SEGUNDO RAMÍREZ, Mario Enrique. Inserción al mercado laboral de los profesionistas de la UACJ: desde el enfoque de la política de ampliación de cobertura. Tesis para obtener el grado de Maestría en Gobierno y Asuntos Públicos. FLACSO-México, 2009.

SENDÓN, María Alejandra. Educación y trabajo: Consideraciones actuales en torno al debate del papel de la educación. Propuesta Educativa, Argentina, año 22, v.2, n.40, p.8-31, nov. 2013.

SOLÍS, Patricio y BLANCO, EMILIO. ¿Relación duradera o divorcio? El vínculo entre la escolaridad y el logro ocupacional temprano en un contexto de deterioro laboral. In: BLANCO, E., SOLÍS, P.; ROBLES, H. Caminos desiguales: trayectorias educativas y

\begin{tabular}{l|l|l} 
v.3 & n.1 & p.66-89
\end{tabular}


laborales de los jóvenes en la Ciudad de México. México: Colegio de México, 2014. p.107129.

UNIVERSIDAD AUTÓNOMA DEL ESTADO DE MÉXICO. Agenda estadística 2015. Disponible en: 2015. En: <http://www.uaemex.mx/planeacion/Agenda.html>. Acceso: 25 mayo 2015.

\section{AGRADECIMIENTOS}

Al Consejo Nacional de Ciencia y Tecnología (Conacyt), por el apoyo para realización de este artículo.

A Belem Carbajal Barroso, responsable del Departamento de Servicios Escolares del CUVT, por su apoyo y asesoría.

n.1

